\title{
Experimental Study on the Atomization and Chemiluminescence Characteristics of Ethanol Flame
}

\author{
Qing Zhang, ${ }^{1,2}$ Xudong Song, ${ }^{1,2}$ Qinghua Guo, ${ }^{1,2}$ Yan Gong, ${ }^{1,2}$ \\ Chonghe $\mathrm{Hu},{ }^{1,2}$ and Guangsuo $\mathrm{Yu}^{1,2}$ \\ ${ }^{1}$ Key Laboratory of Coal Gasification and Energy Chemical Engineering of Ministry of Education, \\ East China University of Science and Technology, Shanghai 200237, China \\ ${ }^{2}$ Shanghai Engineering Research Center of Coal Gasification, East China University of Science and Technology, \\ Shanghai 200237, China \\ Correspondence should be addressed to Yan Gong; yangong@ecust.edu.cn and Guangsuo Yu; gsyu@ecust.edu.cn
}

Received 17 October 2016; Revised 18 December 2016; Accepted 27 December 2016; Published 19 January 2017

Academic Editor: Artem E. Masunov

Copyright (C) 2017 Qing Zhang et al. This is an open access article distributed under the Creative Commons Attribution License, which permits unrestricted use, distribution, and reproduction in any medium, provided the original work is properly cited.

\begin{abstract}
The breakup regime in ethanol diffusion flame under different conditions was studied by the high speed camera system combined with the UV camera system. Spray angle and Weber number (We) were used to represent the change of breakup regime. With the increases of spray angle and We, the breakup mode changes from the Rayleigh-type breakup regime to the superpulsating regime. The reaction area and intensity of ethanol flames under different breakup regimes could be discussed by the $\mathrm{OH}^{*}$ distribution. From Rayleigh-type breakup regime to superpulsating breakup regime, the $\mathrm{OH}^{*}$ distribution increased and the oxidation-reduction reaction area expanded. At the condition of superpulsating breakup mode, the intensity of $\mathrm{OH}^{*}$ was significantly higher than that of other modes. The flame luminous length can be obtained by the $\mathrm{OH}^{*}$ emission, and $\mathrm{OH}^{*}$ distribution reflects the structure of flame. When the breakup regime changes from the fiber-type breakup regime to the superpulsating regime, the flame luminous length increases suddenly.
\end{abstract}

\section{Introduction}

The heterogeneous flame is widely used in many facilities such as internal combustion engines, rockets, gas turbines, boilers, gasifier, and heaters [1-6]. Compared with the homogeneous flame, the heterogeneous flame system is more complex and there are still some important mechanisms that need to be studied. For instance, in the liquid fuel flame, the transformation of liquid into spray is of importance in the combustion process; the size and distribution of liquid droplets affect the flame stability and combustion efficiency $[7,8]$. Reducing the evaporation time of droplets is an effective way to improve combustion efficiency of liquid fuel flames. Good atomization performance can significantly reduce the droplet size, thus shortening the droplet evaporation time. Therefore, the atomization plays a key role in the liquid fuel combustion process $[8,9]$.

Liquid atomization under cold flow conditions has been widely studied both experimentally and theoretically by many researchers, including Rayleigh [10], Reitz and Bracco [9], Villermaux [11], Liu et al. [12], and Zhao et al. [13, 14]. In these atomization studies, the gas Weber number (We), the Reynolds number (Re), and the momentum flux ratio $(M)$ have been considered as the crucial parameters with respect to atomizing the liquid jet. These three parameters can be defined by the following equations $[7,15]$ :

$$
\begin{aligned}
\mathrm{We} & =\frac{\rho_{g}\left(u_{g}-u_{l}\right)^{2} D_{l}}{\sigma}, \\
\operatorname{Re}_{g} & =\frac{\rho_{g} D_{g} u_{g}}{\mu_{g}}, \\
M & =\frac{\rho_{g} u_{g}^{2}}{\rho_{l} u_{l}^{2}},
\end{aligned}
$$

where $u_{l}$ and $\rho_{l}$ are the velocity and density of liquid, respectively, $D_{l}$ is the exit diameter of liquid jet, and $\sigma$ is 
the surface tension. $u_{g}, \mu_{g}$, and $\rho_{g}$ are the velocity, dynamic viscosity, and density of gas, respectively. $D_{g}$ is the equivalent exit diameter of gas jet.

Farago and Chigier [16] applied these parameters to analyze the coaxial air-water jets photographs obtained in the experiment and divided the atomization regime into four modes: the Rayleigh-type breakup, the membranetype breakup, the fiber-type breakup, and the superpulsating breakup. Lasheras and Hopfinger [17] proposed a breakup regime in the parameter space We-Re after summarizing the results in the literature. Lasheras et al. [18] studied the atomization characteristics of liquid jet and their breakup regime results do not agree with the results of Farago and Chigier. Leroux et al. [15] found that injector geometry has some influence on the breakup regimes.

The above researchers have done a lot of studies on liquid atomization and obtained many results; however, most of them are conducted under cold flow conditions. Investigations on hot conditions are relatively less, and the detailed properties of atomization in the flame have not been completely known yet. The major question is whether and how results from cold flow tests can be transferred to hot conditions. Although some researches have made significant contributions to the understanding of the effects of flame and spray behavior, those studies are commonly focused on liquid rocket propulsion system, and the object of study is $\mathrm{LOX} / \mathrm{H}_{2}$ or $\mathrm{LOX} / \mathrm{CH}_{4}$ spray combustion $[8,19-21]$. From this discussion, the limitations of cold flow tests in predicting hot fire atomization become evident, especially the atomization and combustion characteristics of liquid fuel flames.

In the present study, the ethanol flame is used to investigate the characteristics of atomization and chemiluminescence under hot conditions by the high speed camera system combined with the UV camera system. The breakup regimes of ethanol flame were obtained and the application of $\mathrm{OH}^{*}$ chemiluminescence in ethanol flames has been discussed.

\section{Experimental Setup}

2.1. Detection System. Figure 1 shows the schematic diagram of the experimental setup, which contains two parts: jet atomization system and flame detection system. A twochannel burner is used to supply the fuel (absolute ethanol) and oxidizer (pure oxygen). A gear pump (Cole-Parmer, A-73004-00\#) is used to control the ethanol flow rate and transport ethanol into the center channel of the burner; oxygen is transported into the annular channel. The diameter of the center channel is $1.5 \mathrm{~mm}$, and the inner and outer diameters of the oxygen channel are $2.2 \mathrm{~mm}$ and $4.0 \mathrm{~mm}$. The high speed oxygen shears ethanol with an angle of $60^{\circ}$ in the annular channel to start the atomization.

Flame detection system contains high speed camera system and $\mathrm{OH}^{*}$ detection system. The model of the high speed camera is Photron Fastcam APX-RS. The image resolution is $1024 \times 1024$ pixels, the frame rate is set to $3000 \mathrm{fps}$, and the exposure time is $1 / 20000 \mathrm{~s}$. The $\mathrm{OH}^{*}$ emission data was collected by a UV imaging system (Isuzu Optics), which contains three parts: a UV CCD camera (EX-3011B), a UV lens, and a $310 \mathrm{~nm}$ bandpass filter. This UV CCD camera is
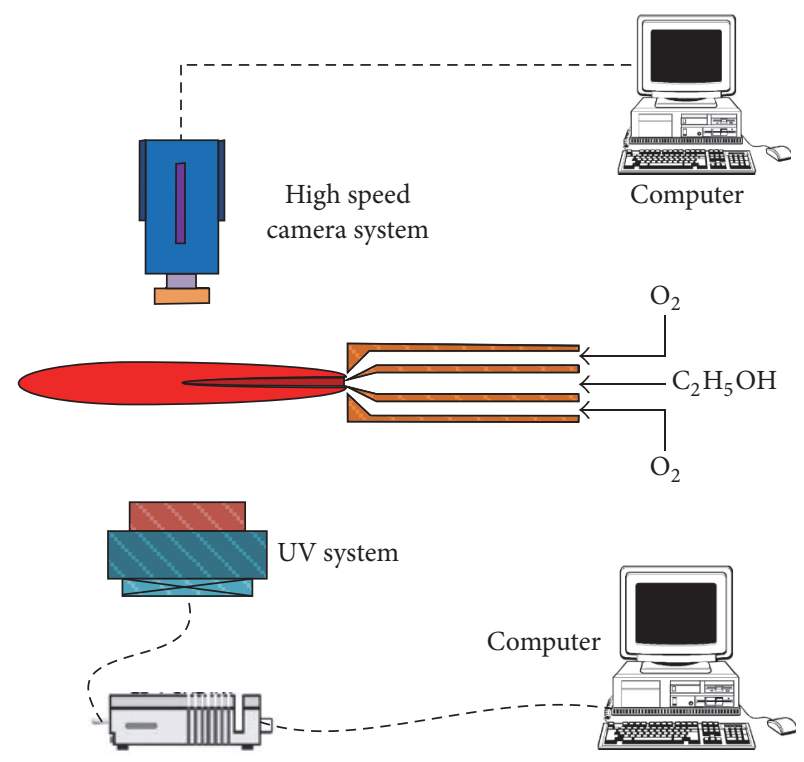

FIgURE 1: The schematic diagram of the experimental setup.

equipped with a cooling system in order to reduce the dark current. An achromatic ultraviolet quartz lens is used to focus the luminescence of the flame. $\mathrm{OH}^{*}$ chemiluminescence is then extracted through a $10 \mathrm{~nm}$ wide bandpass filter centered at $310 \mathrm{~nm}$. More detailed information about this UV imaging system can be found elsewhere [22, 23].

2.2. Experimental Conditions. When the burner structure is fixed, the atomization effect is related to the gas velocity and liquid flow rate. So variable gas velocity and constant gas velocity are used to investigate the change of breakup regime and spectral radiation characteristics in heterogeneous flame.

The oxygen to carbon $(\mathrm{O} / \mathrm{C})$ equivalence ratio $\left([\mathrm{O} / \mathrm{C}]_{\mathrm{e}}\right)$ is defined by the following equation:

$$
[\mathrm{O} / \mathrm{C}]_{\mathrm{e}}=\frac{[\mathrm{O} / \mathrm{C}]_{\mathrm{a}}}{[\mathrm{O} / \mathrm{C}]_{\mathrm{s}}}
$$

where $[\mathrm{O} / \mathrm{C}]_{\mathrm{a}}$ is the actual mole ratio of oxygen to carbon $(\mathrm{O} / \mathrm{C})$ calculated from the feeding flows of fuel and oxygen, and $[\mathrm{O} / \mathrm{C}]_{\mathrm{s}}$ is the stoichiometric $\mathrm{O} / \mathrm{C}$. The $[\mathrm{O} / \mathrm{C}]_{\mathrm{e}}$ is adjusted by the $\mathrm{O}_{2}$ flow rate. Table 1 listed the experimental conditions. The oxygen velocity in the constant gas velocity conditions is 80,100 , and $120 \mathrm{~m} / \mathrm{s}$, respectively. The flow rate of ethanol in variable gas velocity conditions is 1,2 , and $3 \mathrm{~kg} / \mathrm{h}$, respectively.

\section{Results and Discussion}

3.1. Breakup Regimes of Ethanol Flame. Yang et al. [19] found that, with the presence of combustion, atomization becomes more complex with respect to the atomization process in cold flow sprays and there are several controlling parameters that affect the atomization under hot test conditions. In order to find the atomization characteristics in the presence of flame, the photographs of ethanol flames under each experimental condition were captured by the high speed camera. 
TABLE 1: Experimental conditions of ethanol flames.

\begin{tabular}{|c|c|c|c|c|}
\hline Condition & {$[\mathrm{O} / \mathrm{C}]_{\mathrm{e}}$} & Ethanol flow rate $(\mathrm{kg} / \mathrm{h})$ & Oxygen flow rate (L/min) & Oxygen velocity $(\mathrm{m} / \mathrm{s})$ \\
\hline \multicolumn{5}{|c|}{ Variable gas velocity } \\
\hline 1 & 0.60 & \multirow{7}{*}{1.0} & 15 & 28 \\
\hline 2 & 0.70 & & 17 & 32 \\
\hline 3 & 0.80 & & 19 & 37 \\
\hline 4 & 0.90 & & 22 & 42 \\
\hline 5 & 1.00 & & 24 & 46 \\
\hline 6 & 1.10 & & 27 & 51 \\
\hline 7 & 1.20 & & 29 & 56 \\
\hline 8 & 0.60 & \multirow{7}{*}{2.0} & 29 & 56 \\
\hline 9 & 0.70 & & 34 & 65 \\
\hline 10 & 0.80 & & 39 & 74 \\
\hline 11 & 0.90 & & 44 & 83 \\
\hline 12 & 1.00 & & 49 & 93 \\
\hline 13 & 1.10 & & 54 & 102 \\
\hline 14 & 1.20 & & 58 & 111 \\
\hline 15 & 0.60 & \multirow{7}{*}{3.0} & 44 & 83 \\
\hline 16 & 0.70 & & 51 & 91 \\
\hline 17 & 0.80 & & 58 & 111 \\
\hline 18 & 0.90 & & 66 & 125 \\
\hline 19 & 1.00 & & 73 & 139 \\
\hline 20 & 1.10 & & 80 & 153 \\
\hline 21 & 1.20 & & 88 & 167 \\
\hline \multicolumn{5}{|c|}{ Constant gas velocity } \\
\hline 22 & 0.60 & 2.88 & \multirow{7}{*}{42} & \multirow{7}{*}{80} \\
\hline 23 & 0.70 & 2.47 & & \\
\hline 24 & 0.80 & 2.16 & & \\
\hline 25 & 0.90 & 1.92 & & \\
\hline 26 & 1.00 & 1.73 & & \\
\hline 27 & 1.10 & 1.57 & & \\
\hline 28 & 1.20 & 1.44 & & \\
\hline 29 & 0.60 & 3.60 & \multirow{7}{*}{53} & \multirow{7}{*}{100} \\
\hline 30 & 0.70 & 3.09 & & \\
\hline 31 & 0.80 & 2.70 & & \\
\hline 32 & 0.90 & 2.40 & & \\
\hline 33 & 1.00 & 2.16 & & \\
\hline 34 & 1.10 & 1.96 & & \\
\hline 35 & 1.20 & 1.80 & & \\
\hline 36 & 0.60 & 4.32 & \multirow{7}{*}{63} & \multirow{7}{*}{120} \\
\hline 37 & 0.70 & 3.70 & & \\
\hline 38 & 0.80 & 3.24 & & \\
\hline 39 & 0.90 & 2.88 & & \\
\hline 40 & 1.00 & 2.59 & & \\
\hline 41 & 1.10 & 2.36 & & \\
\hline 42 & 1.20 & 2.16 & & \\
\hline
\end{tabular}

Figure 2 shows the representative photographs of different atomization regimes obtained from various experimental conditions. It can be seen that, in the presence of flame, the atomization morphology is similar to that observed under cold flow conditions, which can be classified into four regimes: Rayleigh-type breakup, membrane-type breakup, fiber-type breakup, and superpulsating breakup. For cold flow experiments, the We number, $\operatorname{Re}_{g}$ number, and momentum flux ratio $M$ are very important parameters in the classification of atomization modes. Many researchers used these 


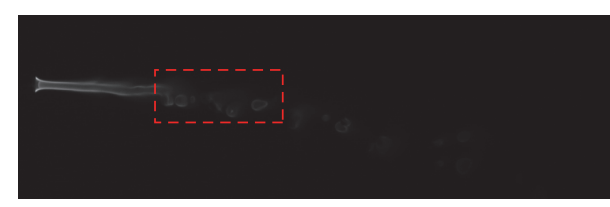

(a) Rayleigh-type breakup, We $=209, M=$ 98, $\mathrm{Re}_{\mathrm{g}}=5795$

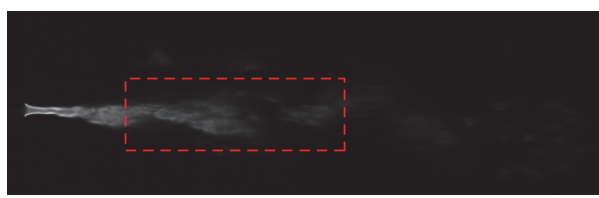

(c) Fiber-type breakup, We $=975, M=98, \mathrm{Re}_{g}=$ 12517

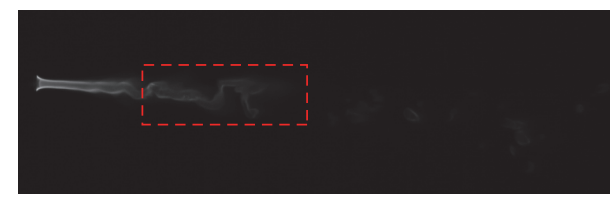

(b) Membrane-type breakup, We $=836, M=$ 98, $\operatorname{Re}_{g}=11589$

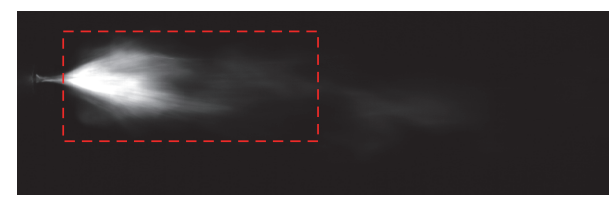

(d) Superpulsation breakup, We $=1880, M=$ 98, $\operatorname{Re}_{g}=17384$

FIGURE 2: Representative photographs of four breakup regimes under hot conditions ((a) condition 5, (b) condition 12, (c) condition 33, and (d) condition 19).

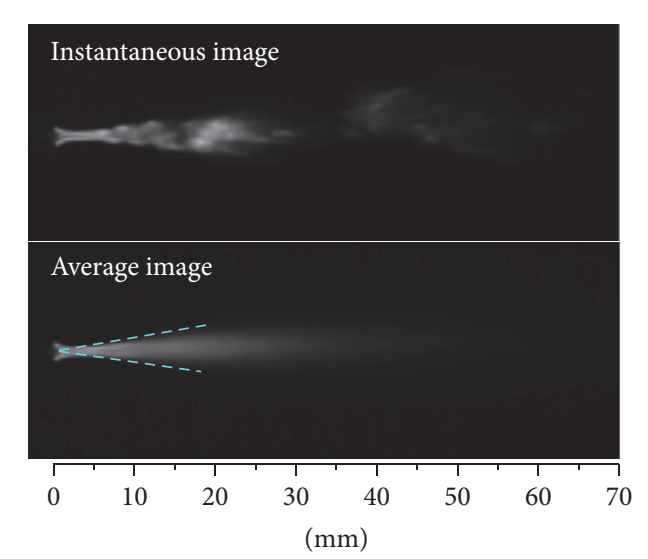

Figure 3: The instantaneous and average images of flame (condition 33).

three parameters to obtain the breakup regime map, such as We-Re ${ }_{g}$ map, We- $M$ map, and $M-\operatorname{Re}_{g}$ map, and the results are good. However these results obtained from cold flow tests cannot be transferred to hot conditions directly. Only using these three parameters is unable to obtain a proper breakup regime map under the experimental conditions of the present study; new parameters should be introduced to characterize the breakup regimes in ethanol flame.

Figure 3 shows the instantaneous and average images of flame under condition 33 . The average image is obtained from 5000 instantaneous images. It can be seen from the average image in Figure 3 that the oxygen shears the ethanol and produces the flame spray angle. The breakup regime can be reflected by the flame spray angle.

Figure 4 shows the flame spray angle as a function of We number. The results show that increasing We number results in an increasing flame spray angle. The data shown in this figure can be divided into four parts, that is, the four breakup regimes of ethanol flame: I, the Rayleigh-type breakup (spray angle $<10^{\circ}$, We $\left.<500\right)$; II, the membrane-type breakup $\left(10^{\circ}<\right.$ spray angle $<25^{\circ}, 500<$ We $<900$ ); III, the fiber-type

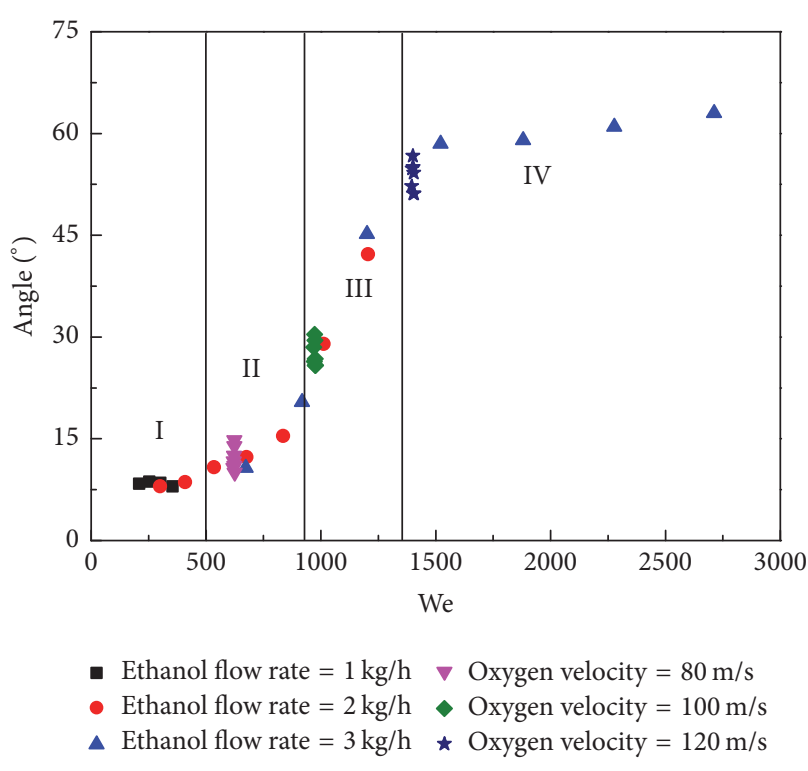

FIgURE 4: Flame spray angle as function of We.

breakup $\left(25^{\circ}<\right.$ spray angle $\left.<50^{\circ}, 900<\mathrm{We}<1300\right)$; and IV, the superpulsating breakup (spray angle $>50^{\circ}$, We $>1300$ ). When the We number and the flame spray angle are both smaller (spray angle $<10^{\circ}$, We $<500$ ), the Rayleigh-type breakup regime occurs. While the We number and the flame spray angle are both larger (spray angle $>50^{\circ}$, We $>1300$ ), the superpulsating breakup regime occurs. The We number and the flame spray angle can reflect the breakup regime clearly. Unlike for We number, no significant correlation of the flame spray angle with either the momentum flux ratio $M$ or the $\mathrm{Re}_{g}$ number has been found.

3.2. Reaction Regions of Ethanol Flame. In the ethanol flame, the oxygen has two functions: shearing the ethanol and reacting with the droplet. Different breakup regimes will produce different droplets, and different size of droplets will 


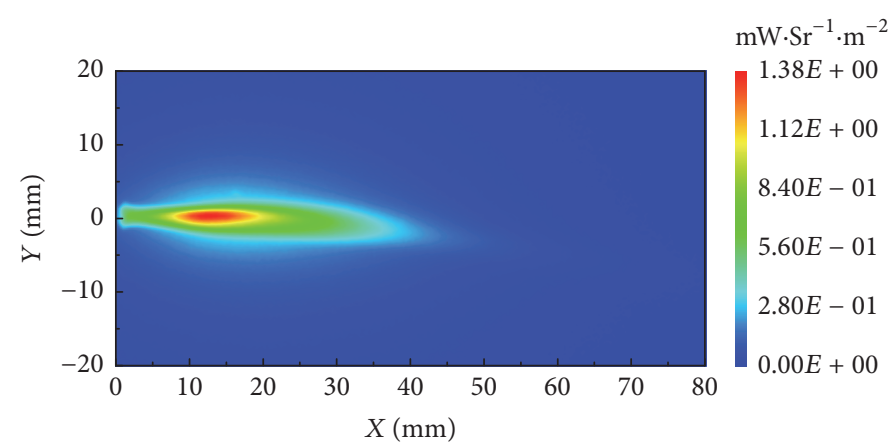

(a) Condition 5

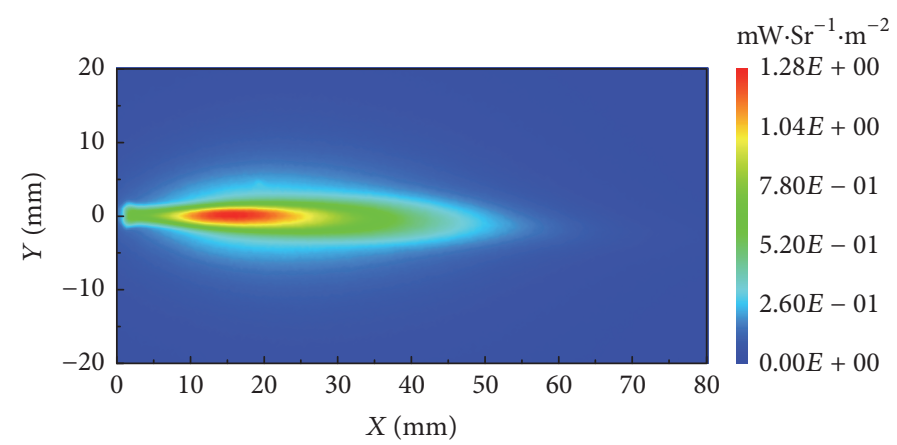

(b) Condition 12

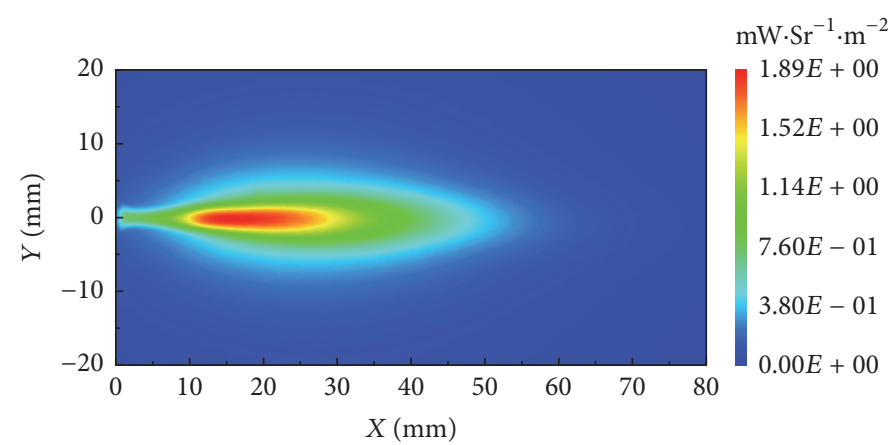

(c) Condition 33

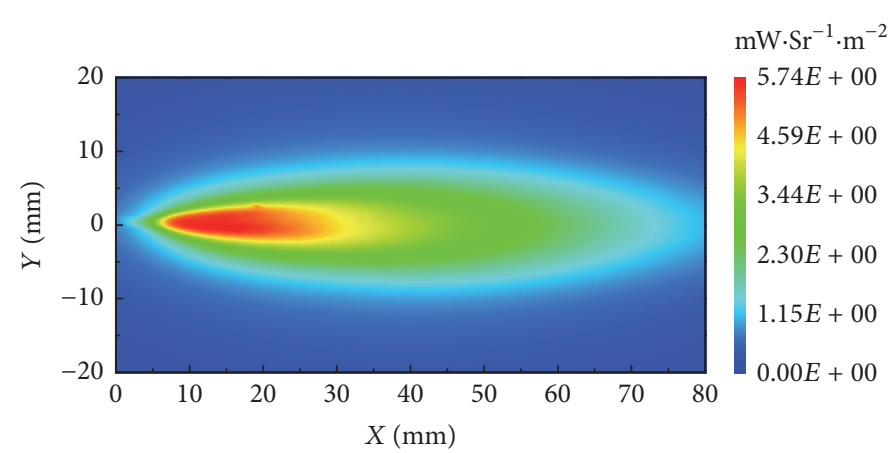

(d) Condition 19

FIGURE 5: $\mathrm{OH}^{*}$ distribution and emission intensity in ethanol flame.

have different reaction time. The gas velocity is very high, and the pace time of droplet is less than $1 \mathrm{~s}$, so the atomization effect influences the reaction in ethanol flame.

Figure 5 shows the $\mathrm{OH}^{*}$ distribution and emission intensity in ethanol flame at different breakup regimes.
From the distribution of $\mathrm{OH}^{*}$, the size of reaction area of the flame can be obtained. In the Rayleigh-type breakup regime (Figure 5(a)), $\mathrm{OH}^{*}$ exists from the burner exit to the downstream. Because of the low oxygen velocity, the size of droplets is very big, and the effect of gravity force 


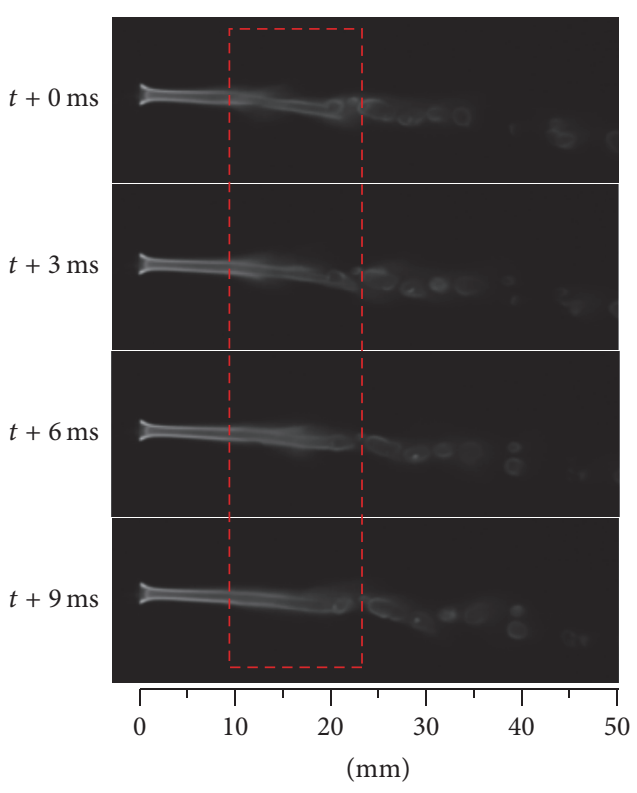

(a) Condition 5

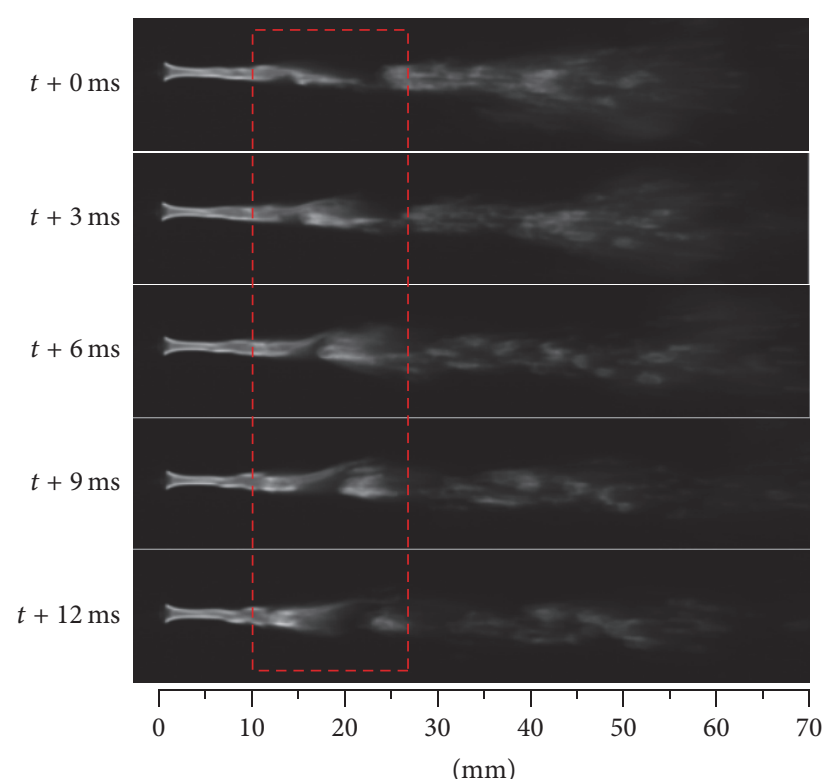

(b) Condition 33

Figure 6: The change of instantaneous images in ethanol flame.

cannot be neglected. In this case, the droplet has the tendency to downward, so the reaction area of the flame is not symmetrical. With the increase of velocity, the size of droplet becomes smaller and the effect of gravity force is neglected, so the reaction area becomes symmetrical. Compared with different breakup regimes, the $\mathrm{OH}^{*}$ intensity first increases and then decreases along the flame propagation direction. At the position about $10 \mathrm{~mm}$ to $30 \mathrm{~mm}$ away from the burner exit $(10 \mathrm{~mm}<X<30 \mathrm{~mm})$, the $\mathrm{OH}^{*}$ peak intensity occurs, and the $\mathrm{OH}^{*}$ radial distribution is the widest. It indicates that more droplet and oxygen react at $10 \mathrm{~mm}<X<30 \mathrm{~mm}$, and a clear reaction center occurs. when $X>30 \mathrm{~mm}$, the fuel and oxygen are consumed gradually, and $\mathrm{OH}^{*}$ intensity decreases, so oxidation-reduction reaction disappears. From Rayleigh-type breakup regime to superpulsating breakup regime, the $\mathrm{OH}^{*}$ distribution increases and the oxidationreduction reaction area expands. At the condition of superpulsating breakup the intensity of $\mathrm{OH}^{*}$ (Figure 5(d)) is higher than that of other modes.

Figure 6 shows the changes of instantaneous images in flame at different conditions. As the $\mathrm{OH}^{*}$ distribution shown in Figure 5(a), $\mathrm{OH}^{*}$ peak intensity exists at the position about $X=20 \mathrm{~mm}$ and the droplet also occurs at this position. At the exit of the burner, more high speed oxygen reacts with the droplet, which makes the heat accumulate and produces impulse. The impulse then takes the droplet to the downstream. Figure 6(a) shows the change of Rayleightype breakup regime at different times. At $t+0 \mathrm{~ms}$, the liquid column begins to fragment at the position $X=20 \mathrm{~mm}$ due to the influence of impulse and shear force. Part of the oxygen reacts with the droplet and produces huge heat. Until $t+9 \mathrm{~ms}$, the liquid column fragment process finishes, and part of hot oxygen reacts with the droplet at the downstream. The flame in the membrane-type breakup regime is similar to that of

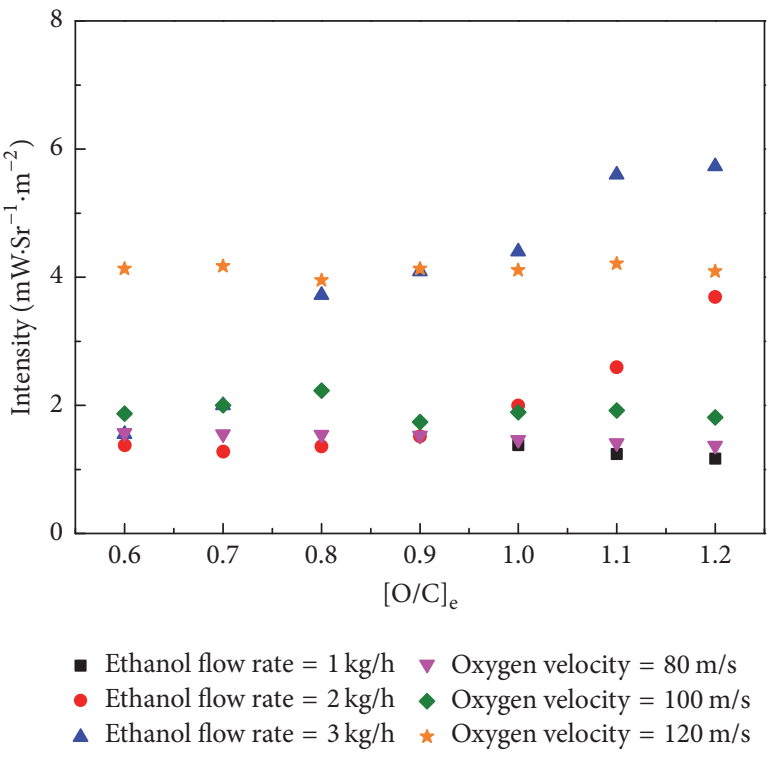

FIGURE 7: $\mathrm{OH}^{*}$ peak emission intensity in ethanol flame.

Rayleigh-type breakup regime. As shown in Figure 6(b), the high velocity has the entraining effect on the droplet and makes the oxygen mix with the droplet. The influence of impulse and shear force makes the reaction expend to the radial direction and then influence the size of the flame spray angle.

Figure 7 shows $\mathrm{OH}^{*}$ peak emission intensity in ethanol flame under different conditions. When the gas velocity is constant, the $\mathrm{OH}^{*}$ peak intensity changes smaller with the increase of $[\mathrm{O} / \mathrm{C}]_{\mathrm{e}}$. According to the atomization photographs obtained by the high speed camera, the atomization 


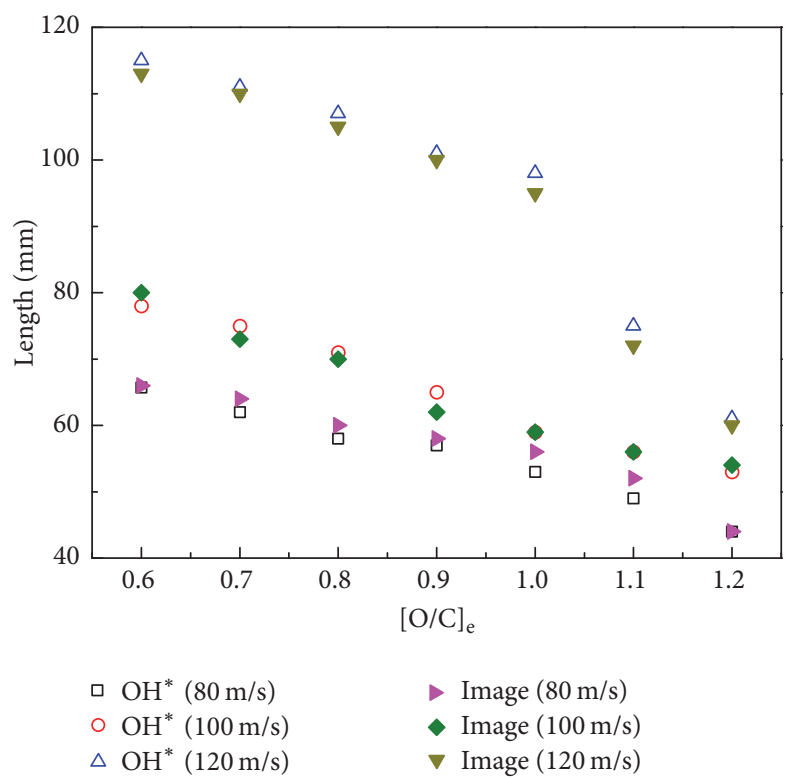

FIGURE 8: Comparison of flame luminous lengths obtained by $\mathrm{OH}^{*}$ emission and flame images.

morphology changes very little with the increase of $[\mathrm{O} / \mathrm{C}]_{\mathrm{e}}$ under the same gas velocity, so the $\mathrm{OH}^{*}$ intensity changes rarely. What is more, although the ethanol flow rate decreases (the oxygen flow rate and velocity are constant) with the increase of $[\mathrm{O} / \mathrm{C}]_{\mathrm{e}}$, the $\mathrm{OH}^{*}$ intensity changes little, which indicates that, under constant gas velocity conditions, the change of ethanol flow rate has little effect on the atomization performance and reaction intensity. The $\mathrm{OH}^{*}$ peak intensity changes a lot when the gas velocity is variable. When the ethanol flow is $1 \mathrm{~kg} / \mathrm{h}$, the $\mathrm{OH}^{*}$ peak intensity has no change, while when the ethanol flow becomes larger, $\mathrm{OH}^{*}$ peak intensity increases with the increase of $[\mathrm{O} / \mathrm{C}]_{\mathrm{e}}$. Combining with the difference of breakup regimes in Figure 4, the gas velocity influences the atomization effect under variable gas velocity conditions. There are different breakup regimes at different gas velocities, which makes $\mathrm{OH}^{*}$ intensity vary greatly.

Figure 8 shows the comparison of flame luminous lengths obtained by the $\mathrm{OH}^{*}$ emission and flame images. The length of flame is the maximal radial distance between the burner exit and the boundary of flame. Flame length gained by the flame image is based on the theory of image segmentation. The image can be divided into two parts by the gray value: the flame region and the background region, and then the length can be calculated. The length obtained by the $\mathrm{OH}^{*}$ emission is the maximal radial distance measured from the $\mathrm{OH}^{*}$ distribution profile. From Figure 8, the lengths gained by the $\mathrm{OH}^{*}$ emission and flame image are almost the same, and the error is less than 5\%. In the ethanol flame, the droplets are wrapped by the oxygen, and reactions occur around the droplets. $\mathrm{OH}^{*}$ exists all over the flame, so the $\mathrm{OH}^{*}$ distribution can reflect the structure of the flame.

Figure 9 shows the comparison of flame luminous lengths gained by the $\mathrm{OH}^{*}$ emission at different conditions. When

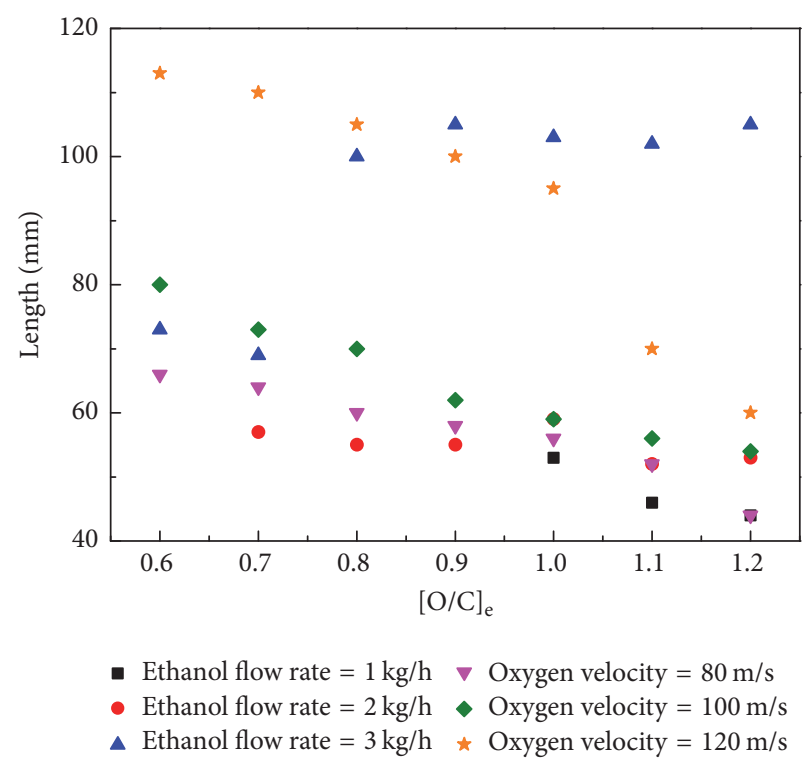

Figure 9: Comparison of flame luminous lengths at different conditions.

the velocity of oxygen is constant, the flame length decreases with the increase of $[\mathrm{O} / \mathrm{C}]_{\mathrm{e}}$, and when the velocity of oxygen is variable, the flame length shows no regular change with the increase of $[\mathrm{O} / \mathrm{C}]_{\mathrm{e}}$. When the velocity is constant, the ethanol decreases with the increase of $[\mathrm{O} / \mathrm{C}]_{\mathrm{e}}$. The breakup regime has no changes, so the number of droplets produced by the ethanol decreases, and the reaction of flame decreases; then the length of flame decreases. When the velocity of oxygen is variable, the breakup regime changes from the Rayleightype breakup to the superpulsating breakup with the increase of $[\mathrm{O} / \mathrm{C}]_{\mathrm{e}}$. When the velocity is low, the type of breakup regime mainly contains the Rayleigh-type breakup and the membrane-type breakup; the size of the droplets is too big to react with the oxygen clearly, so the flame luminous length changes a little with the $[\mathrm{O} / \mathrm{C}]_{\mathrm{e}}$. When the flow rate of ethanol is $3 \mathrm{~kg} / \mathrm{h}$, the breakup regime changes from the fiber-type breakup to the superpulsating breakup with the increase of $[\mathrm{O} / \mathrm{C}]_{e}$, and more droplets react with the oxygen, so the luminous length increases.

\section{Conclusions}

Spray angle and Weber number (We) were used to represent the change of liquid fuel breakup regime. When the spray angle and We were small (spray angle $<10^{\circ}$, We $<500$ ), the Rayleigh-type breakup mode appeared. While the spray angle and We were big enough (spray angle $>50^{\circ}$, We $>1300$ ), the breakup mode changed into the superpulsating regime. The reaction area and intensity of ethanol flames under different breakup regimes could be discussed by the $\mathrm{OH}^{*}$ distribution. From Rayleigh-type breakup regimes to superpulsating breakup regimes, the $\mathrm{OH}^{*}$ distribution increased and the oxidation-reduction reaction area extended. At the condition of superpulsating breakup mode, the intensity of $\mathrm{OH}^{*}$ was higher than that of other modes. The flame luminous lengths 
can be obtained by the $\mathrm{OH}^{*}$ emission. When the velocity of oxygen is constant, the flame luminous length decreases with the increase of $[\mathrm{O} / \mathrm{C}]_{e}$, and when the velocity of oxygen is variable, the flame length shows no regular change with the increase of $[\mathrm{O} / \mathrm{C}]_{\mathrm{e}}$. When the breakup regime changes from the fiber-type breakup to the superpulsating one, the flame luminous length increases suddenly.

\section{Competing Interests}

The authors declare that they have no competing interests.

\section{Acknowledgments}

This work is partially supported by National Natural Science Foundation of China (51406056); the Fundamental Research Funds for the Central Universities (222201514336); and the Shanghai Pujiang Program (15PJD011).

\section{References}

[1] M. G. De Giorgi, A. Sciolti, and A. Ficarella, "Application and comparison of different combustion models of high pressure LOX/CH 4 jet flames," Energies, vol. 7, no. 1, pp. 477-497, 2014.

[2] W. A. Sirignano, "Advances in droplet array combustion theory and modeling," Progress in Energy and Combustion Science, vol. 42, no. 1, pp. 54-86, 2014.

[3] F. Yi and R. L. Axelbaum, "Stability of spray combustion for water/alcohols mixtures in oxygen-enriched air," Proceedings of the Combustion Institute, vol. 34, no. 1, pp. 1697-1704, 2013.

[4] D. C. Haworth, "Progress in probability density function methods for turbulent reacting flows," Progress in Energy and Combustion Science, vol. 36, no. 2, pp. 168-259, 2010.

[5] C. Pera, V. Knop, S. Chevillard, and J. Reveillon, "Effects of residual burnt gas heterogeneity on cyclic variability in leanburn SI engines," Flow, Turbulence and Combustion, vol. 92, no. 4, pp. 837-863, 2014.

[6] C. Pera, V. Knop, and J. Reveillon, "Influence of flow and ignition fluctuations on cycle-to-cycle variations in early flame kernel growth," Proceedings of the Combustion Institute, vol. 35, no. 3, pp. 2897-2905, 2015.

[7] H. Zhao, H.-F. Liu, X.-S. Tian, J.-L. Xu, W.-F. Li, and K.F. Lin, "Influence of atomizer exit area ratio on the breakup morphology of coaxial air and round water jets," AIChE Journal, vol. 60, no. 6, pp. 2335-2345, 2014.

[8] I. Lee, M. Son, and J. Koo, "Atomization and combustion characteristics of ethanol/nitrous oxide at various momentum flux ratios," Energy \& Fuels, vol. 28, no. 4, pp. 2770-2779, 2014.

[9] R. D. Reitz and F. V. Bracco, "Mechanism of atomization of a liquid jet," Physics of Fluids, vol. 25, no. 10, pp. 1730-1742, 1982.

[10] L. Rayleigh, "On the instability of jets," Proceedings of the London Mathematical Society, vol. 10, no. 1, pp. 4-13, 1878.

[11] E. Villermaux, "Unifying ideas on mixing and atomization," New Journal of Physics, vol. 6, no. 6, p. 295, 2004.

[12] H.-F. Liu, X. Gong, W.-F. Li, F.-C. Wang, and Z.-H. Yu, "Prediction of droplet size distribution in sprays of prefilming air-blast atomizers," Chemical Engineering Science, vol. 61, no. 6, pp. 1741-1747, 2006.
[13] H. Zhao, H.-F. Liu, W.-F. Li, and J.-L. Xu, "Morphological classification of low viscosity drop bag breakup in a continuous air jet stream," Physics of Fluids, vol. 22, no. 11, pp. 507-538, 2010.

[14] H. Zhao, H.-F. Liu, J.-L. Xu, W.-F. Li, and W. Cheng, "Breakup and atomization of a round coal water slurry jet by an annular air jet," Chemical Engineering Science, vol. 78, pp. 63-74, 2012.

[15] B. Leroux, O. Delabroy, and F. Lacas, "Experimental study of coaxial atomizers scaling. Part I: dense core zone," Atomization and Sprays, vol. 17, no. 5, pp. 381-407, 2007.

[16] Z. Farago and N. Chigier, "Morphological classification of disintegration of round liquid jets in a coaxial air stream," Atomization and Sprays, vol. 2, pp. 137-153, 1992.

[17] J. C. Lasheras and E. J. Hopfinger, "Liquid jet instability and atomization in a coaxial gas stream," Annual Review of Fluid Mechanics, vol. 32, pp. 275-308, 2000.

[18] J. C. Lasheras, E. Villermaux, and E. J. Hopfinger, "Break-up and atomization of a round water jet by a high-speed annular air jet," Journal of Fluid Mechanics, vol. 357, pp. 351-379, 1998.

[19] B. Yang, F. Cuoco, and M. Oschwald, "Atomization and flames in $\mathrm{LOX} / \mathrm{H}_{2}$ - and $\mathrm{LOX} / \mathrm{CH}_{4}$-spray combustion," Journal of Propulsion and Power, vol. 23, no. 4, pp. 763-771, 2007.

[20] J. J. Smith, G. Schneider, D. Suslov, M. Oschwald, and O. Haidn, "Steady-state high pressure $\mathrm{LO}_{x} / \mathrm{H}_{2}$ rocket engine combustion," Aerospace Science and Technology, vol. 11, no. 1, pp. 39-47, 2007.

[21] W. Mayer and H. Tamura, "Propellant injection in a liquid oxygen/gaseous hydrogen rocket engine," Journal of Propulsion and Power, vol. 12, no. 6, pp. 1137-1147, 1996.

[22] X. D. Song, Q. H. Guo, C. H. Hu, Y. Gong, and G. S. Yu, " $\mathrm{OH}^{*}$ chemiluminescence characteristics and structures of the impinging reaction region in opposed impinging diffusion flames," Energy \& Fuels, vol. 30, no. 2, pp. 1428-1436, 2016.

[23] T. Zhang, G. Yu, Q. Guo, and F. Wang, "Experimental study on the characteristics of impinging reaction region with $\mathrm{OH}^{*}$ chemiluminescence in opposed impinging diffusion flames," Energy \& Fuels, vol. 27, no. 11, pp. 7023-7030, 2013. 

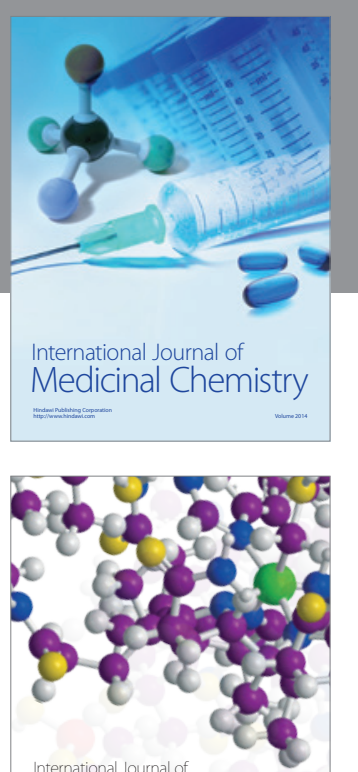

Carbohydrate Chemistry

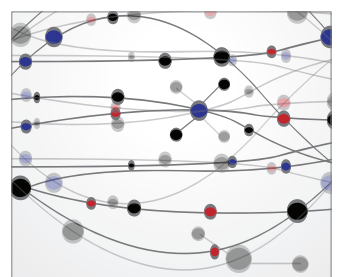

The Scientific World Journal
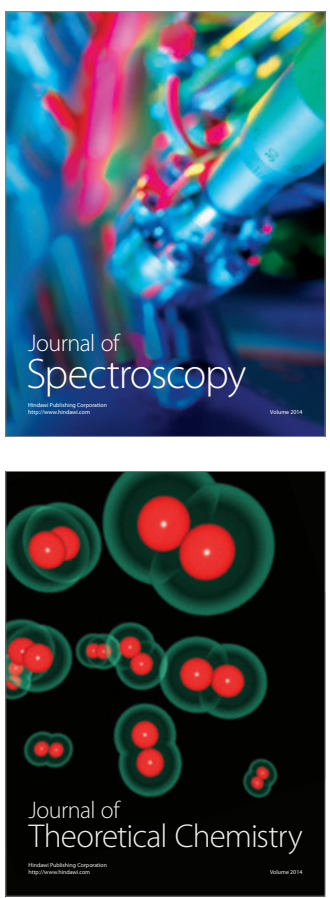
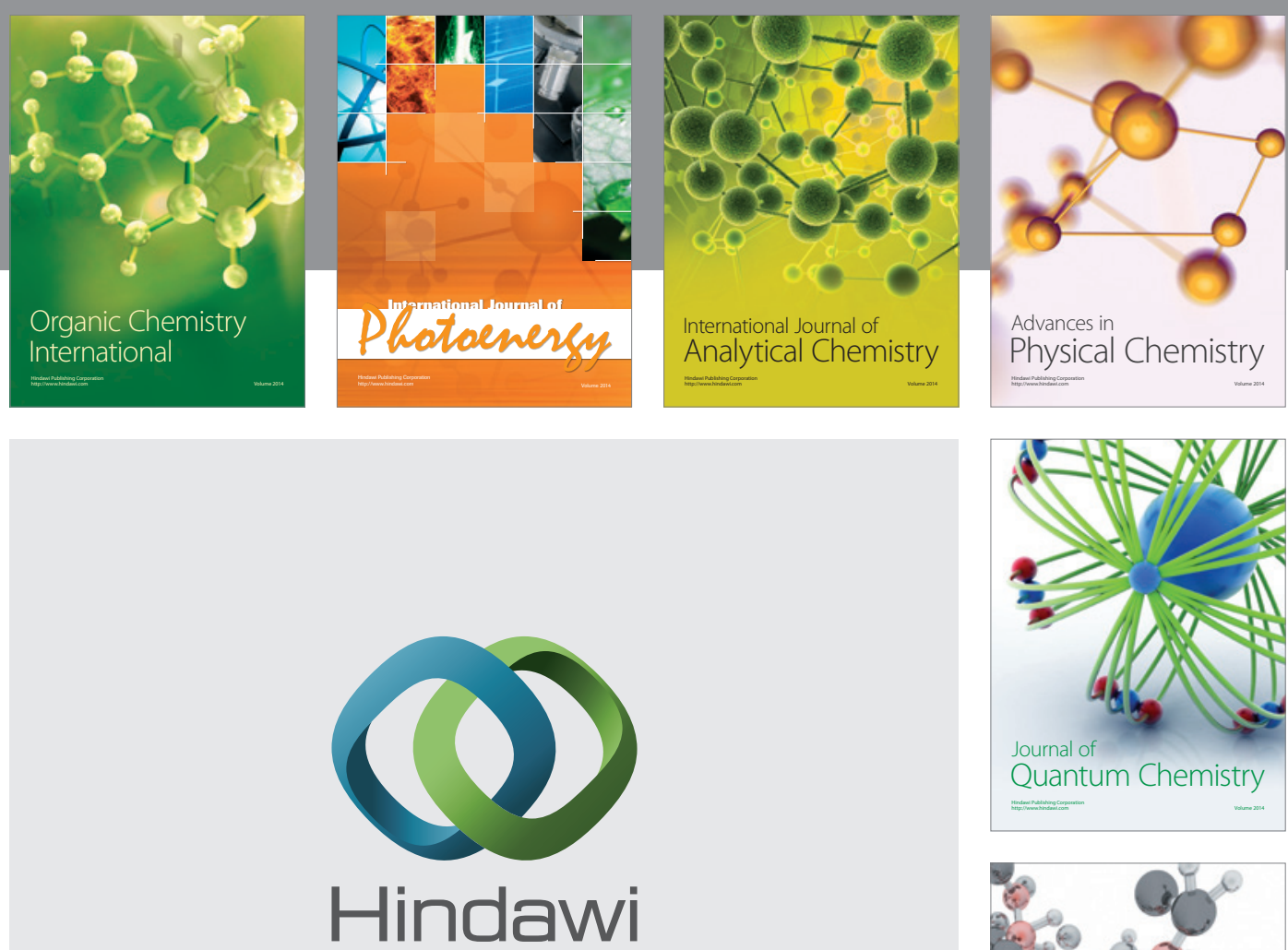

Submit your manuscripts at

https://www.hindawi.com

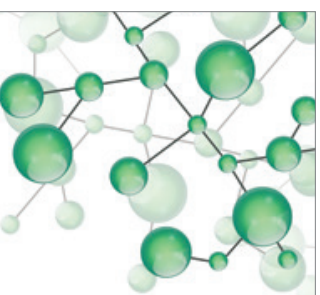

International Journal of

Inorganic Chemistry
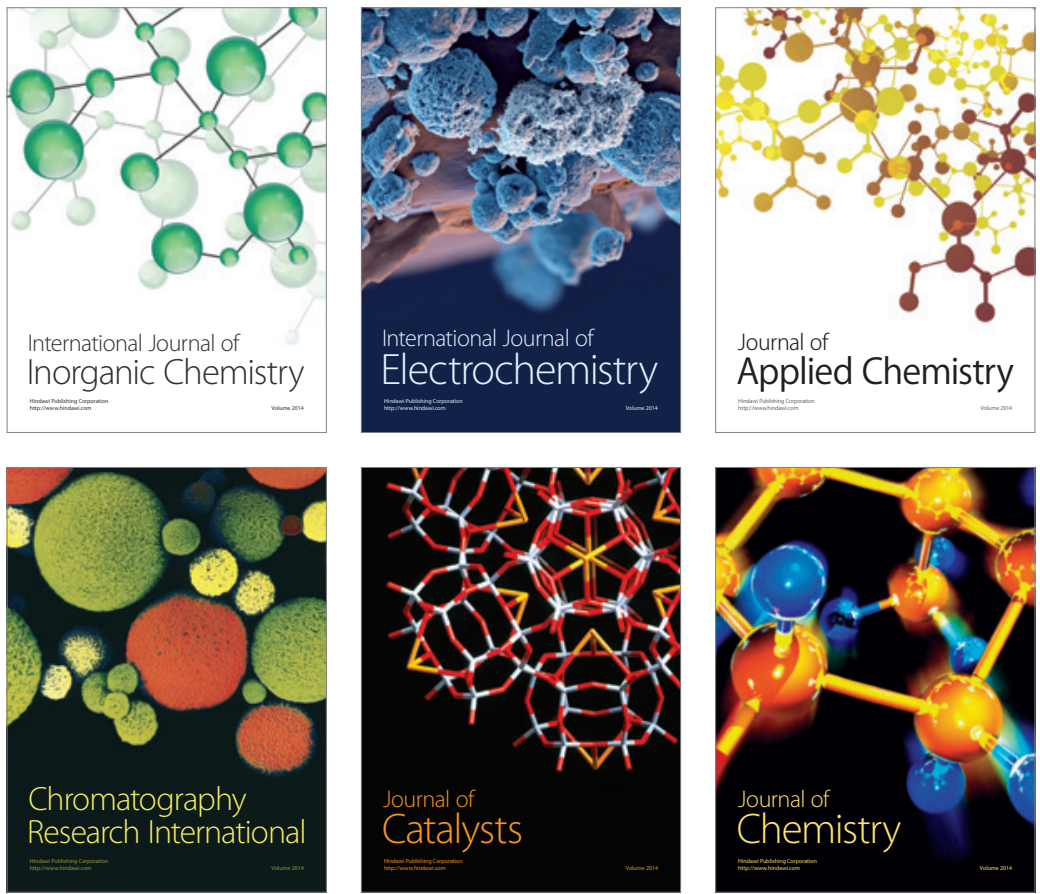

Journal of

Applied Chemistry
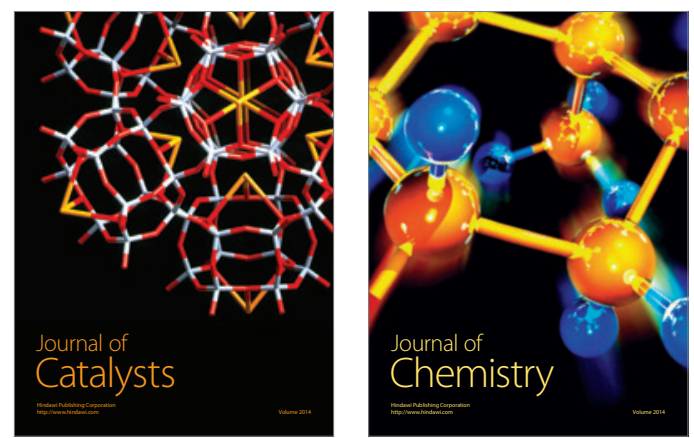
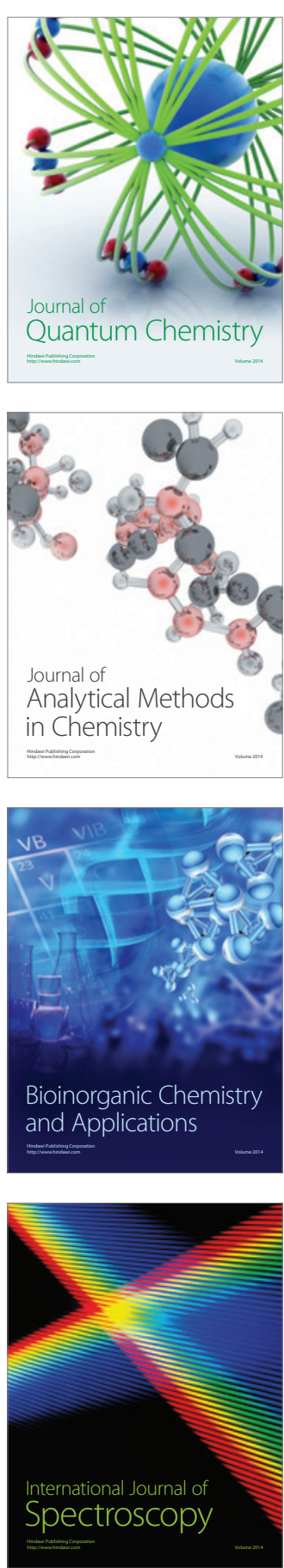